Rev. Bras. Saúde Prod. Anim., Salvador, v.14, n.1, p.195-208 jan./mar., 2013 http://www.rbspa.ufba.br ISSN 15199940

\title{
Qualidade de ovos de codorna submetidos ou não a tratamento superficial da casca armazenados em diferentes ambientes
}

\author{
Quality of quail eggs submitted or no to surface treatment of the shell stored in different \\ environments
}

\begin{abstract}
MENDONÇA, Michele de Oliveira ${ }^{1,2^{*}}$; REIS, Renata de Souza ${ }^{2}$; BARRETO, Sérgio Luiz de Toledo $^{2}$; MUNIZ, Jorge Cunha Lima ${ }^{2}$; VIANA, Gabriel da Silva ${ }^{2}$; MENCALHA, Raquel ${ }^{2}$; FERREIRA, Roberta Corsino ${ }^{2}$; RIBEIRO, Cleverson Luis Nascimento ${ }^{2}$
\end{abstract}

\footnotetext{
${ }^{1}$ Instituto Federal de Educação, Ciência e Tecnologia do Sudeste de Minas Gerais, Departamento de Zootecnia, Rio Pomba, Minas Gerais, Brasil.

${ }^{2}$ Universidade Federal de Viçosa, Centro de Ciências Agrárias, Departamento de Zootecnia, Viçosa, Minas Gerais, Brasil.

*Endereço para correspondência: michele.mendonca@ufv.br
}

\section{RESUMO}

Com o objetivo de avaliar a qualidade de ovos de codornas japonesas tratados superficialmente, através de imersão em óleo mineral ou solução de própolis, foram conduzidos experimentos simultâneos em dois ambientes, sem refrigeração (Experimento 1) e com refrigeração (Experimento 2). Para cada experimento, foram selecionados 360 ovos íntegros distribuídos em delineamento inteiramente casualizado em esquema fatorial 3 x 5 (ovos não tratados; ovos imersos em solução de própolis e ovos imersos em óleo mineral, avaliados durante cinco tempos de armazenamento: $7 ; 14 ; 21 ; 28$ e 35 dias), cada tratamento foi composto por seis repetições de quatro ovos cada. Os ovos apresentaram aumento da perda de peso, diminuição do peso específico e aumento do peso e do $\mathrm{pH}$ da gema, além de redução do $\mathrm{pH}$ do albúmen e de seu respectivo peso com o avançar do tempo de estocagem na ausência de refrigeração (Experimento 1), independente se receberam ou não tratamento na casca. Entretanto, o tratamento superficial com óleo mineral promoveu proteção contra essa perda progressiva de peso e diminuição do peso específico, tornando-as menos intensas com o avançar do período de estocagem sem refrigeração. No Experimento 2, a imersão dos ovos em óleo mineral conferiu menor perda de peso, maior peso específico, maior peso de gema e de albúmen durante o armazenamento sob refrigeração. A qualidade de ovos de codornas submetidos a tratamento superficial da casca por imersão em óleo mineral é preservada por até cinco semanas em diferentes ambientes, sem e com refrigeração.

Palavras-chave: Coturnix, óleo mineral, perda de peso, própolis.

\section{SUMMARY}

With the aim of evaluating the quality of eggs of Japanese quail treated superficially, by immersion in mineral oil or propolis solution, simultaneous experiments were conducted in two environments, without refrigeration (Experiment 1) and with refrigeration (Experiment 2). For each experiment, were selected 360 intact eggs distributed in a completely randomized design in factorial 3 x 5 (untreated eggs; eggs immersed in propolis or eggs immersed in mineral oil, evaluated for five storage times: $7 ; 14 ; 21 ; 28$ and 35 days), each treatment consisted of four replicates of six eggs each. The eggs had increased weight loss, decrease in specific gravity and growth the weight and the $\mathrm{pH}$ of the yolk, besides the reduced the $\mathrm{pH}$ of the albumen and their respective weight with advancing storage time in the absence of cooling (Experiment 1), whether treated or not in the shell. However, the surface treatment with mineral oil promoted protection against progressive loss of weight and decreased specific gravity, making them less intense with advancing the storage period 
without refrigeration. In the Experiment 2, the immersion of eggs in mineral oil promoted less weight loss, higher specific weight, greater weight of the yolk and the albumen during storage under refrigeration. The quality of quail eggs submitted of treatment superficial on shell by immersion in mineral oil is preserved for up to five weeks under different environments, with and without refrigeration.

Keywords: Coturnix, mineral oil, propolis, weight loss.

\section{INTRODUÇÃO}

Como todo produto de origem animal, o ovo é perecível, e começa a perder sua qualidade logo após a oviposição, especialmente na ausência de adequados métodos de armazenamento, como constatado por Wardy et al. (2010). Várias características de qualidade interna são perdidas com a estocagem prolongada do ovo, destacando-se alterações no albúmen e na gema (STADELMAN \& COTTERILL, 1995).

Algumas substâncias, como óleos minerais e vegetais, aplicadas na superfície da casca dos ovos preservam a qualidade interna, bem como estende a vida útil de ovos. Waimaleongora-Ek et al. (2009) observaram que a aplicação de óleo mineral na casca de ovos de galinha reduziu em dez vezes a perda de peso e prolongou a vida de prateleira por mais três semanas comparado com ovos não revestidos em cinco semanas de armazenamento sob $25^{\circ} \mathrm{C}$. No entanto, o uso de óleos minerais como protetores de ovos, pode ser fator de contaminação por metais tais como cobre, zinco e cádmio (SIMÃ̃, 1985).

Uma alternativa ao uso do óleo mineral no prolongamento da qualidade dos ovos é a própolis, resina coletada das árvores pelas abelhas, que contém inúmeras substâncias, com ações antimicrobiana e antifúngica (LONGHINI et al., 2007).
Carvalho (2009) concluiu que o tratamento de ovos de galinha com tintura de própolis aumenta sua vida útil, uma vez que as características físicas e organolépticas foram preservadas por mais tempo.

Aygun et al. (2012) com objetivo de avaliarem os efeitos da própolis sobre a perda de peso de ovos de codornas japonesas destinados a incubação, pulverizaram os ovos com álcool etílico $70 \%$ (grupo A), o segundo grupo recebeu cloreto de benzalcônio (grupo B), e o os ovos do terceiro, quarto e quinto grupo foram pulverizados com soluções de própolis em diferentes concentrações: $5 \%, 10 \%$ e $15 \%$, respectivamente. Os autores constataram que ovos de codornas pulverizados com as diferentes soluções de própolis apresentaram menor perda de peso $(\mathrm{P}$ $<0,001)$ do que os ovos dos grupos A e B. Partindo-se da premissa que a maior parte dos ovos de codornas é comercializada in natura e que a maioria das pesquisas relacionadas à preservação da qualidade dos ovos por tratamento superficial da casca foram realizadas com ovos de galinha, objetivou-se avaliar a qualidade de ovos de codornas japonesas submetidos a tratamento superficial da casca, através da imersão em óleo mineral ou solução de própolis, armazenados em diferentes ambientes, com e sem refrigeração, por cinco semanas.

\section{MATERIAL E MÉTODOS}

Dois experimentos simultâneos, de 28 de agosto a 01 de outubro de 2010, foram conduzidos no setor de Avicultura do Departamento de Zootecnia da Universidade Federal de Viçosa, Viçosa MG, utilizando-se ovos provenientes de codornas japonesas com 16 semanas de 
idade, todas alimentadas com ração única desde o início da postura (Tabela 1).

Tabela 1. Composição da ração fornecida durante o período experimental

\begin{tabular}{|c|c|}
\hline Ingredientes & $\begin{array}{l}\text { Quantidade } \\
(\mathrm{kg})\end{array}$ \\
\hline Milho grão & 57,768 \\
\hline Farelo de Soja (45\%) & 31,395 \\
\hline Óleo & 1,887 \\
\hline Calcário & 6,856 \\
\hline Fosfato bicálcico & 1,120 \\
\hline Sal comum & 0,207 \\
\hline DL- Metionina (99\%) & 0,328 \\
\hline L- Lisina HCL (79\%) & 0,163 \\
\hline L- Triptofano (99\%) & 0,010 \\
\hline Cloreto de colina $(60 \%)$ & 0,100 \\
\hline Suplemento vitaminico ${ }^{a}$ & 0,100 \\
\hline Suplemento mineral $^{\mathrm{b}}$ & 0,050 \\
\hline Antioxidante $^{c}$ & 0,010 \\
\hline Total & 100,00 \\
\hline \multicolumn{2}{|l|}{ Composição calculada: } \\
\hline $\begin{array}{l}\text { Energia metabolizável } \\
(\mathrm{kcal} / \mathrm{kg})\end{array}$ & 2850 \\
\hline Proteína bruta $(\%)$ & 21,30 \\
\hline $\begin{array}{l}\text { Metionina }+ \text { cistina } \\
\text { digestível }(\%)\end{array}$ & 0,861 \\
\hline Lisina digestível (\%) & 1,050 \\
\hline Treonina digestível (\%) & 0,630 \\
\hline Triptofano digestível (\%) & 0,221 \\
\hline Arginina digestível (\%) & 1,218 \\
\hline Cálcio (\%) & 3,000 \\
\hline Fósforo disponível (\%) & 0,310 \\
\hline Sódio (\%) & 0,100 \\
\hline \multicolumn{2}{|c|}{ 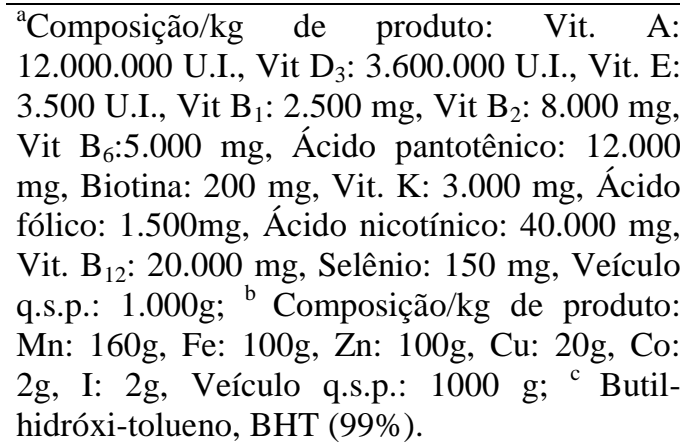 } \\
\hline
\end{tabular}

No Experimento 1, foi avaliado o efeito do tratamento superficial da casca com própolis ou com óleo mineral de ovos de codornas mantidos em ambiente não refrigerado, e no Experimento 2, os ovos tratados (própolis ou óleo mineral) foram armazenados sob refrigeração.

Para cada experimento foram selecionados 360 ovos íntegros individualmente identificados e pesados, distribuídos em um delineamento experimental inteiramente casualizado em esquema fatorial $3 \times 5$ (ovos sem tratamento superficial da casca; ovos que receberam tratamento superficial da casca com própolis e ovos que receberam tratamento superficial da casca com óleo mineral, avaliados em cinco tempos de armazenamento: $7 ; 14$; $21 ; 28$ e 35 dias). Cada tratamento foi composto de seis repetições com quatro ovos cada. Para ambos os experimentos (1 e 2) foram destinados para cada período avaliado $(7 ; 14 ; 21 ; 28$ e 35 dias), 24 ovos por tratamento experimental (sem tratamento da casca, tratamento superficial com própolis e tratamento superficial com óleo mineral).

Para o tratamento com própolis, os ovos foram coletados, selecionados, identificados e imersos em tintura de própolis a 10\% (90\% de álcool de cereais: $10 \%$ de tintura de própolis), conforme descrito por Carvalho (2009). Para o tratamento com óleo mineral, os ovos foram coletados, selecionados, identificados e imersos por cinco minutos em recipiente com óleo mineral puro para consumo humano (Natural, Farmax $^{\circledR}$ ). Os ovos após receberem seus respectivos tratamentos superficiais (própolis ou óleo mineral) foram mantidos em peneira para escorrer o excesso dos produtos, e em seguida foram acondicionados em bandejas plásticas identificadas, sendo então estocados nas respectivas condições de 
cada experimento, sem refrigeração no Experimento $1\left(22,2^{\circ} \mathrm{C}\right.$ - Tabela 2$)$ e em geladeira no Experimento $2\left(6,2^{\circ} \mathrm{C}-\right.$ Tabela 3).

As temperaturas máximas e mínimas e umidade do ar em cada condição experimental foram registradas diariamente pela manhã às $8 \mathrm{~h}$.

Ao final de cada período de armazenamento tanto no Experimento 1 quanto no Experimento 2, foram avaliados: perda de peso dos ovos (\%), peso específico dos ovos $\left(\mathrm{g} / \mathrm{cm}^{3}\right)$, peso (g) e $\mathrm{pH}$ da gema e peso (g) e $\mathrm{pH}$ do albúmen. A perda de peso durante a estocagem foi determinada pela diferença entre o peso de cada ovo no dia zero e no final do tempo de armazenagem através de balança com precisão de 0,001g. Logo após a pesagem, o peso específico dos ovos foi determinado através da imersão dos ovos em soluções salinas com densidade variando de 1,055 a $1,090 \mathrm{~g} / \mathrm{cm}^{3}$, com intervalos de $0,005 \mathrm{~g} / \mathrm{cm}^{3}$, devidamente calibradas por meio de um densímetro $\left(\mathrm{OM}-5565\right.$, Incoterm $\left.{ }^{\circledR}\right)$. Imediatamente após a imersão dos ovos nas soluções citadas anteriormente, os ovos foram quebrados e procedeu-se a separação da gema e do albúmen, a gema foi pesada e feita a medição do $\mathrm{pH}$. O peso do albúmen foi obtido entre a diferença do peso do ovo menos o peso da gema mais o peso da casca, sendo este obtido após lavagem da casca e posterior secagem ao ar por 72 horas. As quatro gemas e os quatro albumens, correspondentes a cada repetição, foram agrupados sendo realizada a análise do pH (pHmetro portátil DM-2P, Digimed ${ }^{\circledR}$ ) de cada componente.

Os dados obtidos de cada parâmetro avaliado foram submetidos a análises estatísticas de acordo com o programa Sistema para Análises Estatísticas e Genéticas (UFV, 2008). Foi realizada análise de variância usando um modelo incluindo os efeitos do tempo de estocagem, do tratamento superficial da casca e da interação entre esses fatores. Em caso de interação significativa optou-se por desdobrar o efeito do tempo de estocagem em cada tratamento superficial da casca por meio de regressão linear e quadrática conforme melhor ajuste obtido para cada parâmetro. $\mathrm{Na}$ ausência de interação, como o tempo de estocagem é uma variável contínua procedeu-se análise de regressão, obtendo a curva que melhor descrevesse $o$ comportamento dos dados. As médias do tratamento superficial da casca dos ovos ao longo do tempo de estocagem foram comparadas pelo teste SNK (StudentNewman-Keuls) a 5\% de probabilidade.

\section{RESULTADOS E DISCUSSÃO}

Ovos de codorna armazenados na ausência de refrigeração (Experimento 1), independente se receberam ou não tratamento superficial na casca, apresentaram aumento da perda de peso, do peso da gema e do $\mathrm{pH}$ da gema e redução no peso específico, do peso do albúmen e do $\mathrm{pH}$ do albúmen com o avançar do tempo de estocagem (Tabela 2).

Véras et al. (2000) constataram que a perda de peso aumenta com o tempo de armazenamento e a intensidade dessas perdas pode aumentar em função da temperatura e umidade.

Segundo a FAO (2003), perda de peso de 2 a $3 \%$ é comum em ovos de galinhas poedeiras comerciais e é dificilmente perceptível pelos consumidores. Verificase que ovos de codornas que não receberam tratamento superficial na casca quando estocados na ausência de refrigeração a partir dos 14 dias de estocagem e os ovos tratados com própolis a partir de 21 dias 
apresentaram valores superiores a 3\% de perda de peso. Entretanto, a perda de peso não foi superior a $2 \%$ nos ovos que receberam tratamento superficial com óleo mineral estocados até 35 dias, mesmo em ambiente não adequado de conservação, ou seja, sem refrigeração.

Ryu et al. (2011) observaram que o óleo mineral e as seis fontes de óleo vegetal estudadas (canola, milho, uva, oliva, soja e girassol) aplicadas superficialmente em ovos de galinha ofereceram uma proteção contra a transferência de umidade e, possivelmente, do $\mathrm{CO}_{2}$ através da casca, minimizando portanto a perda de peso dos ovos $(<0,8 \%)$.

Tabela 2. Temperatura máxima e mínima e umidade relativa registradas durante o período experimental no Experimento 1 (sem refrigeração)

\begin{tabular}{cccc}
\hline \multirow{2}{*}{ Tempo (semana) } & \multicolumn{2}{c}{ Temperatura $\left({ }^{\circ} \mathrm{C}\right)$} & \multirow{2}{*}{ Umidade relativa (\%) } \\
\cline { 2 - 3 } & Mínima & Máxima & $41,4 \pm 7,7$ \\
1 & $16,7 \pm 1,0$ & $24,2 \pm 1,8$ & $36,7 \pm 7,2$ \\
2 & $18,1 \pm 0,9$ & $26,4 \pm 0,4$ & $38,0 \pm 6,1$ \\
3 & $18,9 \pm 1,4$ & $23,6 \pm 1,1$ & $46,4 \pm 7,1$ \\
4 & $21,1 \pm 0,8$ & $24,2 \pm 0,8$ & $58,1 \pm 11,8$ \\
5 & $23,0 \pm 1,9$ & $25,4 \pm 1,0$ & \\
\hline
\end{tabular}

O peso específico reduziu ao longo do tempo de estocagem sob ausência de refrigeração, sendo que os ovos não submetidos a tratamento apresentaram menor peso específico, seguido da aplicação de própolis (Tabela 3), que exibiu ponto mínimo aos 30 dias (Tabela 4). Como observado para a perda de peso, o menor coeficiente angular da reta do peso específico é observado em ovos tratados com óleo mineral, ou seja, há redução neste parâmetro ao longo do tempo de armazenamento, mas de forma menos acentuada que nos demais tratamentos.

De acordo com Mateos \& Beorlegui (1991), em altas temperaturas durante o armazenamento, o ovo transpira, o que intensifica a perda de $\mathrm{CO}_{2}$ e água para o meio, tendo como consequência a perda de peso, aumento progressivo da câmara de ar e redução do peso específico. Este fenômeno se torna mais drástico para ovos armazenados sob temperatura não refrigerada e baixa umidade. No entanto, observa-se que a aplicação superficial com óleo mineral em ovos de codorna promove proteção contra essa perda progressiva de peso $\mathrm{e}$ diminuição do peso específico, tornando-as menos intensas com o avançar do período de estocagem.

Não houve interação dos fatores estudados para o peso da gema que apresentou aumento linear com $\mathrm{o}$ avançar do tempo de estocagem sem refrigeração independente do tratamento superficial na casca $(3,679270+$ $\left.0,010429 \mathrm{x} ; \mathrm{R}^{2}=0,88 ; \mathrm{P}=0,00001\right)$. Durante a estocagem, ocorrem reações físicas e químicas que levam à degradação da estrutura da proteína presente na albumina espessa, tendo como produto das reações, água ligada a grandes moléculas de proteínas que passam para a gema por osmose, aumentando consequentemente seu peso (MATEOS \& BEORLEGUI, 1991). 
Rev. Bras. Saúde Prod. Anim., Salvador, v.14, n.1, p.195-208 jan./mar., 2013 http://www.rbspa.ufba.br ISSN 15199940

Tabela 3. Parâmetros de qualidade de ovos de codornas sem tratamento e tratados superficialmente na casca com solução de própolis a $10 \%$ e óleo mineral armazenados sob condição sem refrigeração avaliados em diferentes períodos de estocagem

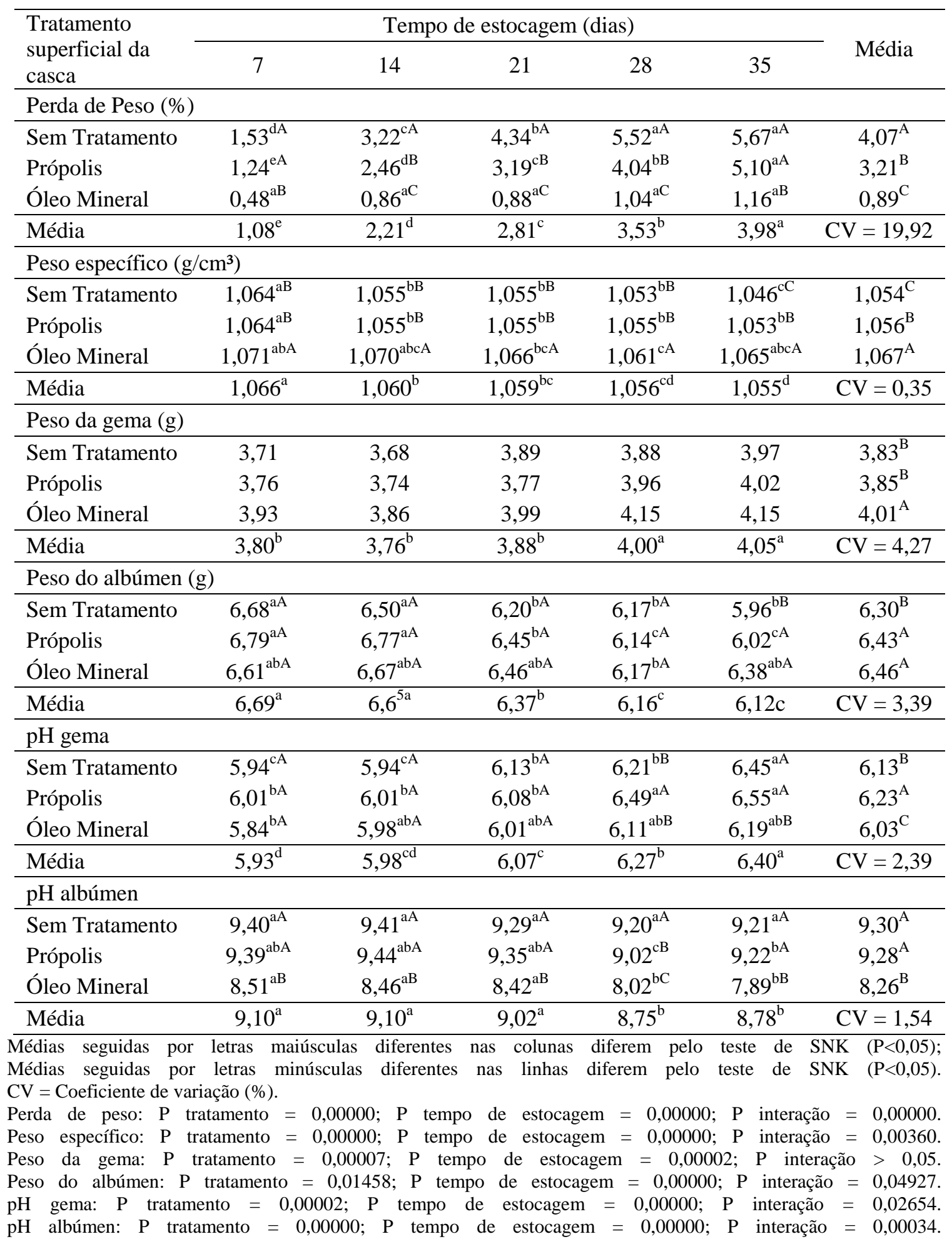


Rev. Bras. Saúde Prod. Anim., Salvador, v.14, n.1, p.195-208 jan./mar., 2013 http://www.rbspa.ufba.br ISSN 15199940

Tabela 4. Equações de regressão dos parâmetros de qualidade de ovos de codornas sem tratamento e tratados superficialmente na casca com solução de própolis a $10 \%$ e óleo mineral armazenados sob condição sem refrigeração avaliados em diferentes períodos de estocagem

\begin{tabular}{lcccc}
\hline $\begin{array}{l}\text { Tratamento superficial da } \\
\text { casca }\end{array}$ & Equação & $\mathrm{R}^{2}$ & $\mathrm{P}$ & $\begin{array}{c}\text { Tempo } \\
\text { (dias) }\end{array}$ \\
\hline Perda de peso (\%) & & & & \\
\hline Sem Tratamento & $-0,634130+0,341760 \mathrm{x}-0,004557 \mathrm{x}^{2}$ & 0,99 & 0,00000 & 37 \\
Própolis & $0,416950+0,132849 \mathrm{x}$ & 0,99 & 0,00000 & - \\
Óleo Mineral & $0,417859+0,022261 \mathrm{x}$ & 0,90 & 0,02902 & - \\
\hline Peso específico $\left(\mathrm{g} / \mathrm{cm}^{3}\right)$ & & & & \\
\hline Sem Tratamento & $1,065730-0,000539 \mathrm{x}$ & 0,89 & 0,00000 & - \\
Própolis & $1,069370-0,001077 \mathrm{x}+0,000018 \mathrm{x}^{2}$ & 0,86 & 0,03339 & 30 \\
Óleo Mineral & $1,072270-0,000271 \mathrm{x}$ & 0,65 & 0,00018 & - \\
\hline Peso do albúmen $(\mathrm{g})$ & & & & \\
\hline Sem Tratamento & $6,834030-0,025330 \mathrm{x}$ & 0,96 & 0,00000 & - \\
Própolis & $7,083640-0,0309506 \mathrm{x}$ & 0,94 & 0,00000 & - \\
Óleo Mineral & $6,747650-0,013810 \mathrm{x}$ & 0,58 & 0,00092 & - \\
\hline pH da gema & & & & \\
\hline Sem Tratamento & $5,751170+0,018262 \mathrm{x}$ & 0,92 & 0,00000 & - \\
Própolis & $5,994330-0,006116 \mathrm{x}+0,000671 \mathrm{x}^{2}$ & 0,89 & 0,04341 & 5 \\
Óleo Mineral & $5,772000+0,012048 \mathrm{x}$ & 0,97 & 0,00004 & - \\
\hline pH do albúmen & & & & \\
\hline Sem Tratamento & $9,476000-0,008286 \mathrm{x}$ & 0,84 & 0,00172 & - \\
Própolis & $9,50667-0,006667 \mathrm{x}$ & 0,50 & 0,00009 & - \\
Óleo Mineral & & & & \\
\hline & $8,509330+0,007242 \mathrm{x}-0,000741 \mathrm{x}^{2}$ & 0,93 & 0,01844 & 5 \\
\hline
\end{tabular}

Souza \& Souza (1995) observaram para ovos de codorna armazenados em duas temperaturas e analisados semanalmente até 21 dias após a postura, que a qualidade da gema (índice de gema) e a qualidade do albúmen (Unidade Haugh) apresentaram resultados similares sob temperatura mais baixa, no entanto, em temperatura elevada, ambas as análises tiveram acentuada queda.

Independente do tratamento superficial na casca, os ovos apresentaram redução no peso do albúmen com o avançar do tempo de armazenagem sem refrigeração, porém essa diminuição foi mais marcante para ovos não submetidos a tratamento superficial, constatado pela diminuição de 2,0 e $2,5 \%$ no peso do albúmen em relação aos ovos tratados com própolis e óleo mineral, respectivamente (Tabela 3 ) e pelo maior coeficiente angular da reta em comparação àqueles que receberam aplicação de óleo mineral (Tabela 4), o que demonstra mais uma vez a eficiência do óleo mineral em amortizar a evaporação da água através da casca. Mateos \& Beorlegui (1991) mencionam que os fatores que mais afetam a qualidade do albúmen são as condições e tempo de armazenamento dos ovos. $\mathrm{O}$ $\mathrm{CO}_{2}$ dissolvido no albúmen durante o processo de formação do ovo, após a oviposição, passa a atmosfera como consequência de um gradiente negativo de concentração. Essa perda de $\mathrm{CO}_{2}$ causa aumento do $\mathrm{pH}$ e fluidificação do albúmen. A fluidificação, por ser 
processo bioquímico, é acelerada com o aumento da temperatura. Além disso, com o calor o ovo transpira e perde, ainda mais, $\mathrm{CO}_{2}$ e água.

$\mathrm{O} \mathrm{pH}$ da gema aumentou de forma linear com o tempo de estocagem para ovos que não receberam tratamento e para aqueles tratados com óleo mineral, e de forma quadrática para os ovos submetidos a aplicação de própolis, tendo seu ponto de menor valor aos cinco dias de armazenamento. Isso acontece, segundo Shang et al. (2004), em função dos íons alcalinos provenientes do albúmen possivelmente serem trocados com íons $\mathrm{H}^{+}$presentes na gema com elevação do $\mathrm{pH}$ da gema. De acordo com os autores, essa variação de $\mathrm{pH}$ poderia induzir a desnaturação das proteínas e aumentar a consistência da gema.

Com a progressão do tempo de estocagem, os valores encontrados para o pH do albúmen de ovos que receberam tratamento superficial com óleo mineral evidenciaram aumento quadrático (ponto de máximo aos cinco dias). Para os demais ovos, não tratados e tratados superficialmente com própolis, observou-se redução linear nos valores de $\mathrm{pH}$ do albúmen com o aumento no tempo de armazenagem, entretanto para ovos tratados com própolis a redução do $\mathrm{pH}$ da clara é menos intensa comparado a ovos que não receberam tratamento, demonstrado pelo coeficiente angular das retas, de 0,006667 e 0,008286, respectivamente.

Souza \& Souza (1995) observaram valores reduzidos para $\mathrm{pH}$ da clara de ovos de codorna mantidos na ausência de refrigeração de 9,0 para 8,9 após 21 dias de estocagem. Já Baptista (2002) constatou pequena elevação no valor de pH do albúmen de ovos de codornas armazenados em local sem refrigeração de 9,23 para 9,64, depois de 27 dias de armazenamento. Akyurek \& Okur
(2009) também observaram aumento no $\mathrm{pH}$ do albúmen de ovos de galinha em função do tempo de armazenamento e da temperatura de conservação, e esse efeito se pronunciou de forma mais evidente a $20^{\circ} \mathrm{C}$.

A redução mais acentuada do $\mathrm{pH}$ do albúmen de ovos de codornas tratados com óleo mineral verificado neste estudo, corrobora com os resultados obtidos por Ryu et al. (2011), que notaram que o $\mathrm{pH}$ do albúmen de ovos de galinha revestidos com óleo mineral diminuiu gradualmente de 8,71 para 7,96 após 15 semanas de armazenamento sob $25^{\circ} \mathrm{C}$. Segundo os autores, os valores de $\mathrm{pH}$ da clara de ovos que receberam aplicação de óleo (mineral ou vegetal) foram significativamente menores $\mathrm{em}$ comparação a ovos não revestidos durante cinco semanas de armazenamento à $25^{\circ} \mathrm{C}$. Isso indica que o selamento dos poros da casca promovido pela aplicação superficial com óleo mineral reduz a saída de $\mathrm{CO}_{2}$ do ovo, que é responsável pelo incremento do $\mathrm{pH}$ do albúmen ao longo do período de estocagem.

Constata-se que a perda de qualidade é um fenômeno inevitável que acontece de forma contínua ao longo do tempo e pode ser agravada, segundo Barbosa et al. (2008), por diversos fatores, como contaminação microbiológica, umidade alta e refrigeração inadequada (acima de $8^{\circ} \mathrm{C}$ ), entretanto verifica-se que a aplicação de óleo mineral na casca de ovos de codorna pode reduzir a velocidade dessa perda de qualidade com o avançar do tempo de estocagem na ausência de refrigeração (Tabela 5).

A perda de peso de ovos sem tratamento e os que receberam aplicação de própolis ou óleo mineral estocados sob refrigeração (Experimento 2) aconteceu de forma linear, porém mais acentuada naqueles ovos que não receberam tratamento na casca (Tabela 6 e 7). 
Jirangrat et al. (2010) observaram que, no armazenamento sob $4^{\circ} \mathrm{C}$, ovos de galinha que receberam óleo mineral na casca apresentaram menor perda de peso ao fim de 15 semanas em relação àqueles que não foram tratados após cinco semanas de armazenamento sob a mesma condição $(1,19 \%$ contra $4,11 \%)$. Isso evidencia mais uma vez a propriedade que o óleo mineral confere aos ovos quanto a sua conservação, uma vez que ao promover uma espécie de selagem dos poros da casca acaba por retardar a perda de peso dos ovos. No estudo de Torrico et al. (2011), a perda de peso (de $0,72 \%$ a $1,20 \%$ ) dos ovos revestidos com óleo mineral e quatro emulsões de óleo mineral e quitosana após cinco semanas de armazenamento a $25^{\circ} \mathrm{C}$ foi significativamente $(\mathrm{P}<0,05)$ mais baixo, após mesmo período de estocagem, de ovos não revestidos $(4,17 \%)$ porém a $4^{\circ} \mathrm{C}$. O que indica, de acordo com os autores que, durante as cinco primeiras semanas de armazenamento, a refrigeração por si só não foi suficiente para manter a perda de peso abaixo do nível recomendado pela FAO (2003), que é de 2 a 3\%. O mesmo foi constatado neste estudo com ovos de codornas em que aqueles que não receberam tratamento superficial na casca mantidos por 35 dias sob refrigeração apresentaram perda de peso acima de 3,0\%, assim como os ovos tratados superficialmente com própolis. No entanto, observa-se que a perda de peso (de 0,48 a $1,16 \%$ sob condição não refrigerada - Tabela 3 , e de 0,27 a $1,04 \%$ em ambiente com refrigeração Tabela 6) de ovos tratados com óleo mineral apresentou significativamente menor nos dois ambientes de armazenamento.

Santos et al. (2009) observaram significativa $(\mathrm{P}<0,05)$ perda de peso de ovos de galinha estocados durante 21 dias, independente da temperatura (ambiente $\left[27,84^{\circ} \mathrm{C}\right]$ ou refrigeração $\left.\left[4,65^{\circ} \mathrm{C}\right]\right)$, comparado aos ovos com sete e 14 dias de armazenamento, fato atribuído pelos autores à redução de água da clara, pois sua proporção diminui linearmente em função da estocagem, sendo mais acentuada nos ovos mantidos em temperatura ambiente.

Nota-se, portanto que a perda de peso dos ovos é inevitável ao longo do tempo de estocagem mesmo sob refrigeração, uma vez que há perda de umidade e $\mathrm{CO}_{2}$ através da casca do ovo, porém em menor intensidade comparado a estocagem sem refrigeração.

Tabela 5. Temperatura máxima e mínima e umidade relativa registradas durante o período experimental no Experimento 2 (com refrigeração)

\begin{tabular}{cccc}
\hline \multirow{2}{*}{ Tempo (semana) } & \multicolumn{2}{c}{ Temperatura $\left({ }^{\circ} \mathrm{C}\right)$} & $\begin{array}{c}\text { Umidade } \\
\text { Relativa }(\%)\end{array}$ \\
\cline { 2 - 3 } & Mínima & Máxima & $74,5 \pm 14,4$ \\
2 & $0,0 \pm 3,1$ & $12,8 \pm 4,5$ & $87,5 \pm 12,0$ \\
3 & $1,2 \pm 0,6$ & $11,7 \pm 2,9$ & $89,8 \pm 13,1$ \\
4 & $0,2 \pm 0,7$ & $9,4 \pm 1,8$ & $88,7 \pm 7,9$ \\
5 & $0,3 \pm 0,7$ & $10,8 \pm 1,4$ & $92,0 \pm 9,3$ \\
\hline
\end{tabular}


Rev. Bras. Saúde Prod. Anim., Salvador, v.14, n.1, p.195-208 jan./mar., 2013 http://www.rbspa.ufba.br ISSN 15199940

Tabela 6. Parâmetros de qualidade de ovos de codornas sem tratamento e tratados superficialmente na casca com solução de própolis a $10 \%$ e óleo mineral armazenados sob refrigeração avaliados em diferentes períodos de estocagem

\begin{tabular}{|c|c|c|c|c|c|c|}
\hline \multirow{2}{*}{$\begin{array}{l}\text { Tratamento } \\
\text { superficial da } \\
\text { casca }\end{array}$} & \multicolumn{5}{|c|}{ Tempo de estocagem (dias) } & \multirow{2}{*}{ Média } \\
\hline & 7 & 14 & 21 & 28 & 35 & \\
\hline \multicolumn{7}{|l|}{ Perda de Peso (\%) } \\
\hline Sem Tratamento & $1,17^{\mathrm{eA}}$ & $1,97^{\mathrm{dA}}$ & $2,77^{\mathrm{cA}}$ & $3,28^{\mathrm{bA}}$ & $3,98^{\mathrm{aA}}$ & $2,63^{\mathrm{A}}$ \\
\hline Própolis & $0,74^{\mathrm{cB}}$ & $1,13^{\mathrm{cB}}$ & $1,77^{\mathrm{bB}}$ & $2,14^{\mathrm{bB}}$ & $3,14^{\mathrm{aB}}$ & $1,78^{\mathrm{B}}$ \\
\hline Óleo Mineral & $0,27^{\mathrm{bC}}$ & $0,35^{\mathrm{bC}}$ & $0,38^{\mathrm{bC}}$ & $0,44^{\mathrm{bC}}$ & $1,04^{\mathrm{aC}}$ & $0,50^{\mathrm{C}}$ \\
\hline Média & $0,73^{\mathrm{e}}$ & $1,15^{\mathrm{d}}$ & $1,64^{\mathrm{c}}$ & $1,95^{\mathrm{b}}$ & $2,72^{\mathrm{a}}$ & $\mathrm{CV}=21,84$ \\
\hline \multicolumn{7}{|c|}{ Peso específico $\left(\mathrm{g} / \mathrm{cm}^{3}\right)$} \\
\hline Sem Tratamento & 1,066 & 1,057 & 1,055 & 1,055 & 1,053 & $1,057^{\mathrm{C}}$ \\
\hline Própolis & 1,068 & 1,062 & 1,059 & 1,054 & 1,054 & $1,059^{\mathrm{B}}$ \\
\hline Óleo Mineral & 1,074 & 1,070 & 1,070 & 1,067 & 1,066 & $1,069^{\mathrm{A}}$ \\
\hline Média & $1,069^{\mathrm{a}}$ & $1,063^{\mathrm{b}}$ & $1,061^{\mathrm{b}}$ & $1,059^{\mathrm{c}}$ & $1,057^{\mathrm{c}}$ & $\mathrm{CV}=0,36$ \\
\hline \multicolumn{7}{|l|}{ Peso da gema (g) } \\
\hline Sem Tratamento & 3,73 & 3,51 & 3,60 & 3,67 & 3,82 & $3,67^{\mathrm{B}}$ \\
\hline Própolis & 3,78 & 3,48 & 3,70 & 3,66 & 3,89 & $3,70^{\mathrm{AB}}$ \\
\hline Óleo Mineral & 3,77 & 3,63 & 3,67 & 3,81 & 3,98 & $3,77^{\mathrm{A}}$ \\
\hline Média & $3,76^{\mathrm{b}}$ & $3,54^{\mathrm{c}}$ & $3,66^{\mathrm{b}}$ & $3,71^{\mathrm{b}}$ & $3,90^{\mathrm{a}}$ & $\mathrm{CV}=4,24$ \\
\hline \multicolumn{7}{|c|}{ Peso do albúmen (g) } \\
\hline Sem Tratamento & 6,69 & 6,84 & 6,52 & 6,53 & 6,32 & $6,58^{\mathrm{B}}$ \\
\hline Própolis & 6,87 & 7,04 & 6,71 & 6,66 & 6,43 & $6,74^{\mathrm{A}}$ \\
\hline Óleo Mineral & 6,82 & 6,95 & 6,89 & 6,69 & 6,47 & $6,76^{\mathrm{A}}$ \\
\hline Média & $6,79^{\mathrm{b}}$ & $6,94^{\mathrm{a}}$ & $6,71^{\mathrm{bc}}$ & $6,63^{c}$ & $6,41^{\mathrm{d}}$ & $\mathrm{CV}=2,89$ \\
\hline \multicolumn{7}{|l|}{ pH gema } \\
\hline Sem Tratamento & $5,95^{\mathrm{bcA}}$ & $5,91^{\mathrm{cA}}$ & $5,89^{\mathrm{cA}}$ & $6,15^{\mathrm{abA}}$ & $6,06^{\mathrm{abcB}}$ & 5,99 \\
\hline Própolis & $5,88^{\mathrm{cA}}$ & $5,85^{\mathrm{cA}}$ & $5,90^{\mathrm{cA}}$ & $6,06^{\mathrm{bA}}$ & $6,28^{\mathrm{aA}}$ & 5,99 \\
\hline Óleo Mineral & $5,93^{\mathrm{bA}}$ & $5,83^{\mathrm{bA}}$ & $5,95^{\mathrm{bA}}$ & $6,09^{\mathrm{aA}}$ & $6,11^{\mathrm{aB}}$ & 5,98 \\
\hline Média & $5,92^{\mathrm{a}}$ & $5,86^{\mathrm{b}}$ & $5,91^{\mathrm{b}}$ & $6,10^{\mathrm{a}}$ & $6,15^{\mathrm{a}}$ & $\mathrm{CV}=1,72$ \\
\hline \multicolumn{7}{|l|}{ pH albúmen } \\
\hline Sem Tratamento & $9,16^{\mathrm{abA}}$ & $9,18^{\mathrm{abA}}$ & $8,92^{\mathrm{bA}}$ & $9,02^{\mathrm{abA}}$ & $8,64^{\mathrm{cA}}$ & $8,98^{\mathrm{A}}$ \\
\hline Própolis & $9,06^{\mathrm{abcA}}$ & $9,13^{\mathrm{abA}}$ & $8,95^{\mathrm{abcA}}$ & $8,90^{\mathrm{bcA}}$ & $8,76^{\mathrm{cA}}$ & $8,96^{\mathrm{A}}$ \\
\hline Óleo Mineral & $8,69^{\mathrm{aB}}$ & $8,50^{\mathrm{bB}}$ & $8,47^{\mathrm{bB}}$ & $8,34^{\mathrm{bB}}$ & $8,30^{\mathrm{bB}}$ & $8,46^{\mathrm{B}}$ \\
\hline Média & $8,97^{\mathrm{a}}$ & $8,94^{\mathrm{a}}$ & $8,78^{\mathrm{b}}$ & $8,75^{\mathrm{b}}$ & $8,56^{\mathrm{c}}$ & $\mathrm{CV}=1,56$ \\
\hline \multicolumn{7}{|c|}{$\begin{array}{l}\text { Médias seguidas por letras maiúsculas diferentes nas colunas diferem pelo teste de } \mathrm{SNK}(\mathrm{P}<0,05) \text {. } \\
\text { Médias seguidas por letras minúsculas diferentes nas linhas diferem pelo teste de } \mathrm{SNK}(\mathrm{P}<0,05) \text {. } \\
\mathrm{CV}=\text { Coeficiente de variação }(\%) \text {. } \\
\text { Perda de peso: } \mathrm{P} \text { tratamento }=0,00000 ; \mathrm{P} \text { tempo de estocagem }=0,00000 ; \mathrm{P} \text { interação }=0,00000 \text {. } \\
\text { Peso específico: } \mathrm{P} \text { tratamento }=0,00000 ; \mathrm{P} \text { tempo de estocagem }=0,00000 ; \mathrm{P} \text { interação }=0,25298 \text {. } \\
\text { Peso da gema: } \mathrm{P} \text { tratamento }=0,03579 ; \mathrm{P} \text { tempo de estocagem }=0,00002 ; \mathrm{P} \text { interação }>0,05 \text {. } \\
\text { Peso do albúmen: } \mathrm{P} \text { tratamento }=0,00083 ; \mathrm{P} \text { tempo de estocagem }=0,00000 ; \mathrm{P} \text { interação }>0,05 . \\
\text { pH gema: } \mathrm{P} \text { tratamento }>0,05 ; \mathrm{P} \text { tempo de estocagem }=0,00000 ; \mathrm{P} \text { interação }=0,01047 . \\
\text { pH albúmen: } \mathrm{P} \text { tratamento }=0,00000 ; \mathrm{P} \text { tempo de estocagem }=0,00000 ; \mathrm{P} \text { interação }=0,03367 \text {. }\end{array}$} \\
\hline
\end{tabular}


Rev. Bras. Saúde Prod. Anim., Salvador, v.14, n.1, p.195-208 jan./mar., 2013 http://www.rbspa.ufba.br ISSN 15199940

Tabela 7. Equações de regressão dos parâmetros de qualidade de ovos de codornas sem tratamento e tratados superficialmente na casca com solução de própolis a $10 \%$ e óleo mineral armazenados sob refrigeração avaliados em diferentes períodos de estocagem

\begin{tabular}{lcccc}
\hline $\begin{array}{l}\text { Tratamento superficial } \\
\text { da casca }\end{array}$ & Equação & $\mathrm{R}^{2}$ & $\mathrm{P}$ & Tempo (dias) \\
\hline Perda de peso (\%) & & & & \\
Sem Tratamento & $0,554934+0,098884 \mathrm{x}$ & 0,99 & 0,00000 & - \\
Própolis & $0,042207+0,082873 \mathrm{x}$ & 0,97 & 0,00000 & - \\
Óleo Mineral & $0,006445+0,023374 \mathrm{x}$ & 0,69 & 0,00069 & - \\
\hline pH da gema & $5,854830+0,006488 \mathrm{x}$ & 0,43 & 0,00105 & - \\
Sem Tratamento & $6,002000-0,023469 \mathrm{x}+0,000899 \mathrm{x}^{2}$ & 1,00 & 0,00021 & 13 \\
Própolis & $5,799500+0,008786 \mathrm{x}$ & 0,70 & 0,00002 & - \\
Óleo Mineral & & & & \\
\hline pH do albúmen & $9,134670+0,008663 \mathrm{x}-0,000620 \mathrm{x}^{2}$ & 0,82 & 0,04571 & 7 \\
Sem Tratamento & $9,212000-0,012048 \mathrm{x}$ & 0,83 & 0,00002 & - \\
Própolis & $8,741880-0,013507 \mathrm{x}$ & 0,94 & 0,00001 & - \\
Óleo Mineral & & & & \\
\hline
\end{tabular}

O peso específico dos ovos, em condição de refrigeração, não foi influenciado pela interação dos fatores estudados (Tabela 6), porém reduziu de forma quadrática (Tabela 8) com o avançar do tempo de estocagem (ponto de mínimo aos 37 dias de armazenamento). Já a aplicação de óleo mineral propiciou, significativamente, maior peso específico comparado a ovos sem tratamento e tratados com própolis, isso pode estar relacionado com a menor perda de peso dos ovos tratados com óleo mineral, pois o selamento dos poros da casca feito por esse produto restringiu a evaporação da água contida no ovo contribuindo para a menor perda de peso e maior peso específico ao longo da estocagem sob refrigeração.

Tabela 8. Equações de regressão dos parâmetros de qualidade de ovos de codornas armazenados sob refrigeração avaliados em diferentes períodos de estocagem

\begin{tabular}{lcccc}
\hline Parâmetro & \multicolumn{1}{c}{ Equação } & $\mathrm{R}^{2}$ & $\mathrm{P}$ & $\begin{array}{c}\text { Tempo } \\
\text { (dias) }\end{array}$ \\
\hline Peso específico $(\mathrm{g} / \mathrm{cm})$ & $1,075110-0,000971 \mathrm{x}+0,000013 \mathrm{x}^{2}$ & 0,98 & 0,00853 & 37 \\
Peso da gema $(\mathrm{g})$ & $3,953800-0,039270 \mathrm{x}+0,001085 \mathrm{x}^{2}$ & 0,86 & 0,00001 & 18 \\
Peso do albúmen $(\mathrm{g})$ & $6,729670+0,20028 \mathrm{x}-0,000845 \mathrm{x}^{2}$ & 0,90 & 0,00087 & 12 \\
\hline
\end{tabular}

A redução no peso específico ou gravidade específica pode estar relacionada com a perda de peso durante o armazenamento. De acordo com fórmula para o cálculo da densidade $(\mathrm{d}=\mathrm{massa} /$ volume $)$, densidade e massa são grandezas diretamente proporcionais e, dessa forma, quando ocorre decréscimo na massa, simultaneamente, ocorre decréscimo na densidade (BARBOSA et al., 2008). Consequentemente, a 
maior perda de massa dos ovos ao longo do período de armazenagem resultou em menor gravidade específica, independente se receberam ou não tratamento superficial na casca (Tabela $6)$.

O tratamento superficial da casca de ovos de codorna com óleo mineral seguido do tratamento superficial com própolis proporcionou maiores pesos de gema e de albúmen comparados aos ovos que não receberam tratamento quando estocados sob refrigeração (Tabela 6), o que pode ser explicado pela minimização da perda de água através dos poros da casca, ocluídos após o tratamento com óleo mineral ou própolis. Aygun et al. (2012) obtiveram os mesmos resultados, menor perda de água, em ovos de codornas incubáveis pulverizados com 5, 10 ou $15 \%$ de própolis.

Não se observou interação significativa para peso de gema e peso de albúmen entre o tratamento superficial da casca e o tempo de estocagem sob refrigeração. Verificou-se aumento e redução de forma quadrática, respectivamente, para peso de gema (ponto de mínimo aos 18 dias) e peso de albúmen (ponto de máximo aos 12 dias) com o avanço do tempo de armazenagem (Tabela 8). Scott \& Silversides (2000) relataram que a porcentagem de albúmen diminui com o avanço da estocagem dos ovos. Como consequência, as porcentagens de gema e casca aumentam em função da redução do peso do ovo e da porcentagem de albúmen (GARCIA et al., 2010). O acréscimo e a diminuição nas proporções de gema e de clara, respectivamente, com o tempo de estocagem podem ser atribuídos a transferência de água do albúmen para a gema, como também verificado com ovos de galinha por Barbosa et al. (2008) e Garcia et al. (2010).
O óleo mineral aplicado na casca de ovos de codorna conferiu menor perda de peso, maior peso específico, maior peso de gema e de albúmen durante o período de armazenamento contribuindo para a conservação da qualidade dos ovos de codornas estocados sob refrigeração. Também é importante destacar os efeitos positivos deste tratamento sob a perda de peso e o peso específico de ovos armazenados sem refrigeração, que apresentaram melhores resultados em todos os períodos avaliados.

A qualidade de ovos de codornas submetidos a tratamento superficial da casca com óleo mineral é preservada por até cinco semanas em diferentes ambientes de armazenamento, sem e com refrigeração.

\section{REFERÊNCIAS}

AKYUREK, H.; OKUR, A.A. Effect of storage time, temperature and hen age on egg quality in free-range layers hens. Journal of Animal and Veterinary Advances, v.8, n.10, p.1953-1958, 2009.

AYGUN, A; SERT, D.; COPUR, G. Effects of propolis on eggshell microbial activity, hatchability, and chick performance in Japanese quail (Coturnix coturnix japonica) eggs.

Poultry Science, v. 91, p.1018-1025, 2012.

\section{BAPTISTA, R.F. Avaliação da qualidade interna de ovos de codorna (Coturnix coturnix japônica) em função da variação da temperatura de armazenamento. 2002. 95p. Dissertação (Mestrado em Medicina Veterinária) - Universidade Federal Fluminense, Niterói.}


Rev. Bras. Saúde Prod. Anim., Salvador, v.14, n.1, p.195-208 jan./mar., 2013 http://www.rbspa.ufba.br ISSN 15199940

BARBOSA, N.A.A.; SAKOMURA, N.K.; MENDONÇA, M.O; FREITAS, E.R. FERNANDES, J.B.K. Qualidade de ovos comerciais provenientes de poedeiras comerciais armazenados sob diferentes tempos e condições de ambientes. ARS Veterinária, v.24, n.2, p.127-133, 2008.

CARVALHO, J.X. Influência da própolis na vida de prateleira de ovos de galinha. Revista Brasileira de Agroecologia, v.4, n.2, p.718-720, 2009.

FOOD AND AGRICULTURE ORGANIZATION OF THE UNITED NATIONS - FAO. Egg marketing: a guide for the production and sale of eggs. Rome, Italy, 2003. (Bulletin, 150).

GARCIA, E.R.M.; ORLANDI, C.C.B.; OLIVEIRA, C.A.L.; CRUZ, F.K.; SANTOS, T.M.B.; OTUTUMI, L.K. Qualidade de ovos de poedeiras semipesadas armazenados em diferentes temperaturas e períodos de estocagem.

Revista Brasileira de Saúde e Produção Animal [online], v.11, n.2, p.505-518, 2010.

JIRANGRAT, W.; TORRICO, D.D.; NO, J.; NO, H.K.;

PRINYAWIWATKUL, W. Effects of mineral oil coating on internal quality of chicken eggs under refrigerated storage. International Journal of Food Science \& Technology, v.45, p.490-495, 2010.

LONGHINI, R.; RAKSA, S.M.; OLIVEIRA, A.C.P.; SVIDZINSKI, T.I.E.; FRANCO, S.L. Obtenção de extratos de própolis sob diferentes condições e avaliação de sua atividade antifúngica. Revista Brasileira de Farmacognosia, v.17, p.388-395, 2007.
MATEOS, G.G.; BEORLEGUI, C.B Nutricion y alimentacion de gallinas ponedoras. Madrid: Mundi-Prensa, 1991. 263p.

RYU, K.N.; NO, H.K.;

PRINYAWIWATKUL, W. Internal quality and shelf life of eggs coated with oils from different sources. Journal of Food Science, v.76, p.325329, 2011. Supl.

SANTOS, M.S.V.; ESPÍNDOLA, G.B.; LÔBO, R.N.B.; FREITAS, E.R.; GUERRA, J.L.L.; SANTOS, A.B.E. Efeito da temperatura e estocagem em ovos. Ciência e Tecnologia de Alimentos, v.29, n.3, p.513-517, 2009.

SCOTT, T.A.; SILVERSIDES, F.G. The effect of storage and strain of hen on egg quality. Poultry Science, v.79, n.12, p.1725-1729, 2000.

SHANG, X.G.; WANG, F.L.; LI, D.F.; YIN, D.J.; LI, J.Y. Effects of dietary conjugated linoleic acid on the productivity of laying hens and egg quality during refrigerated storage.

Poultry Science, v.83, n.10, p.16881695, 2004.

\section{SIMÃO, A.M. Aditivos para} alimentos sob o aspecto toxicológico. São Paulo: Nobel, 1985. 274p.

SOUZA, H.B.A.; SOUZA, P.A. Efeito da temperatura de estocagem sobre a qualidade interna de ovos de codorna armazenados durante 21 dias.

Alimentos e Nutrição, v.6, p.7-13, 1995.

STADELMAN, W.J.; COTTERILL, O.J. Egg science and technology. New York/London: Food Products Press, 1995. 323p. 
TORRICO, D.D.; NO, H.K.;

PRINYAWIWATKUL, W.; JANES, M.; CORREDOR, J.A.; OSORIO, L.F. Mineral oil-chitosan emulsion coatings affect quality and shelf-life of coated eggs during refrigerated and room temperature storage. Journal of Food Science, v.76, p.262-268, 2011. Supl.

UNIVERSIDADE FEDERAL DE VIÇOSA - UFV. Sistema de análises estatísticas e genéticas - SAEG.

Versão 9.1. Viçosa, MG, 2008. 142p.

VÉRAS, A.L.; VELLOSO, C.B.O.; MATIOTTI, T. G.; FARIA, T.C.

Avaliação da qualidade interna de ovos armazenados em dois ambientes em diferentes tempos. Revista Brasileira de Ciência Avícola, v.5, p.55, 2000. Supl.
WAIMALEONGORA-EK, P.; GARCIA, K.; NO, H.K.;

PRINYAWIWATKUL, W.; INGRAM, D. Selected quality and shelf-life of eggs coated with mineral oil with different viscosities. Journal of Food Science, v.74, p.423-429, 2009. Supl.

WARDY, W.; TORRICO, D.D.; NO, H.K.; PRINYAWIWATKUL, W.; SAALIA, F.K. Edible coating affects physic-functional properties and shelf life of chicken eggs during refrigerated and room temperature storage.

International Journal of Food Science \& Technology, v.45, p.2659-2668, 2010.

Data de recebimento: 07/08/2012

Data de aprovação: 14/03/2013 